\title{
Sistem Konten Pembelajaran di Indonesia : Systematic Literature Review
}

\author{
Insanur Hanifuddin $^{1}$, Dhomas Hatta Fudholi ${ }^{2}$, Sri Mulyati ${ }^{3}$ \\ 1,2,3 Program Studi Teknik Informatika, Universitas Islam Indonesia, Yogyakarta, Indonesia \\ ${ }^{1} 17523022 @$ students.uii.ac.id, ${ }^{2}$ hatta.fudholi@uii.ac.id, ${ }^{3}$ mulya@uii.ac.id \\ Diterima 13 Februari 2021 \\ Disetujui 16 Juni 2021
}

\begin{abstract}
Wikipedia is the largest web-based digital encyclopedia today that contains almost all general knowledge. With Systematic Literature Review (SLR), this research examines Wikipedia, other encyclopedias and other online media that contain certain topics with target users in order to find out the potential and need to build a learning content system. The study was conducted on literature related to Wikipedia, encyclopedias, education and children's interests, especially at the elementary school level. Literature search was done by entering several main keywords in Google Scholar such as "Wikipedia", "encyclopedia", "elementary school curriculum", "educational content" and "learning media". Literature is also obtained through the official website of the Ministry of Education and Culture which contains education standards for elementary and junior high schools, educational assessment standards, as well as literacy and numeracy learning modules at the elementary level. The results of the literature analysis include 4 classifications based on topics, namely evaluation of use, content, online learning and media. Based on the results of the analysis of $\mathbf{3 0}$ papers, it was found 9 papers discussing content, 14 papers discussing content in specific fields, and 12 references discussing online media, so it is known that there has not been much research on digital encyclopedias for education.
\end{abstract}

Index Terms-education, encyclopedia, online learning, wikipedia

\section{Pendahuluan}

Wikipedia merupakan ensiklopedia terbesar di dunia dan merupakan salah satu situs web yang paling populer ${ }^{1}$, dengan lebih dari lima ratus juta kunjungan per hari [1]. Dalam konteks pendidikan, ensiklopedia daring seperti Wikipedia memiliki potensi yang sangat baik untuk digunakan sebagai media pembelajaran yang sesuai kurikulum.

Media pembelajaran untuk anak-anak dapat diwujudkan dalam bentuk yang beragam, salah satunya adalah ensiklopedia. Ensiklopedia merupakan wadah dari kumpulan pengetahuan dan informasi yang pada umumnya ditampilkan dengan teks atau gambar. Media pembelajaran daring diharapkan dapat menjadi media untuk jangka panjang meskipun

${ }^{1}$ https://ahrefs.com/blog/most-visited-websites/ pembelajaran secara tatap muka sudah dapat dilaksanakan kembali.

Media pembelajaran daring mendukung siswa dalam belajar secara mandiri dan mengkontruksi pengetahuannya. Pada umumnya pembelajaran daring menggunakan media ruang guru [25], sehingga dari penelitian tersebut diketahui bahwa belum banyak yang memanfaatkan ensiklopedia daring seperti Wikipedia untuk menjadi platform pembelajaran secara spesifik.

Berdasarkan pencarian, ada satu literatur [2] yang membahas tentang perancangan ensiklopedia untuk anak usia 9-12 tahun tentang ekologi dan lingkungan tentang manusia dan lingkungannya, namun masih dalam bentuk buku. Belum banyak penelitian yang membahas tentang ensiklopedia digital, namun sudah ada satu penelitian mengenai ensiklopedia digital tentang dunia tumbuhan [3]. Dalam konteks pembelajaran daring ditemukan beberapa literatur yang relevan seperti literatur [4]-[6] namun tidak dalam bentuk ensiklopedia daring.

Penelitian yang dibangun akan menggunakan metode Systematic Literatur Review (SLR), agar memudahkan dalam menemukan literatur sesuai dengan tujuan maka, literatur diklasifikasikan sesuai instrumen penelitian.

Padahal di jaman pandemik ini, setiap lapisan pendidikan melakukan pembelajaran secara daring. untuk itu Sistem Konten Pembelajaran disini disebut dengan Ensiklopedia daring penting untuk di buat untuk mendukung dalam proses pembelajaran,saat pandemi ini pelajar dituntut untuk mampu balajar mandri sehingga sistem ini dapat digunakan sebagai bahan rekonstruksi pemahaman materi

Pada pendidikan tingkat dasar memiliki karakteristk pembelajaran yang menyeluruh dan belum terfokus pada bidang disiplin ilmu. yang bagi masyarakat umum sering dilupakan karena belum dianggap penting untuk itu kajian ini bertujuan untuk mengetahui hal hal penting dalam membangun ensiklopedia daring yang khusus untuk anak sekolah dasar dengan konten yang sesuai dengan kurikulum 2013. 


\section{METODE}

Pada bagian ini kajian pustaka dilakukan dengan metode Systematics Literature Review dengan mengadopsi pada [31] . Berikut ini gambaran dari tahapan penelitian :

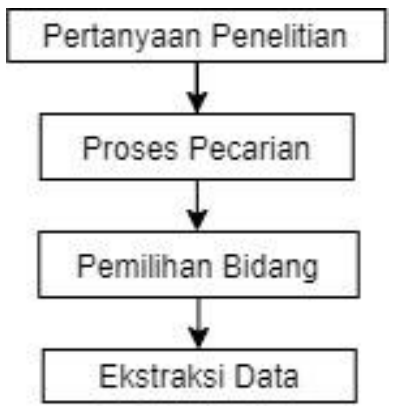

Gambar 1. Tahapan Penelitian

Berikut ini penjelasan terkait tahapan penelitian yang dilakukan :

1. Pertanyaan Penelitian

Pertanyaan penelitian yang harapannya dapat menemukan tujuan penelitian adapun pertanyaan penelitiannya adalah:

a) Bagaimana kondisi evaluasi pengguna terkait penggunaan media pembelajaran?

b) Bagaimana cakupan dari bidang ilmu pada konten media pembelajaran

c) Bagaimana peranan media pembelajaran yang diterapkan?

d) Apa saja bentuk media pembelajaran yang digunakan?

\section{Proses Pencarian}

Pencarian literatur sesuai topik yang membahas tentang Wikipedia, ensiklopedia, pendidikan dasar dan media pembelajaran daring.

\section{Pemilihan Bidang}

Kemudian penulis melakukan pemilihan paper yang relevan berdasarkan paper yang diambil dengan mendefinisikan bahwa makalah harus mengambarkan media daring dan sistem konten pembelajaran. Pada jenjang pendidikan kami merujuk pada Permendikbud No 67 Tahun 2013 terkait kerangkadansar dan struktur kurikulum 2013 dan memilih untuk tingkat sekolah yang memiliki karakteristik pembelajaran menyeluruh dan belum terpusat pada salah satu bidang, maka jenjang pendidikan dasar yang sesuai.

\section{Ekstraksi Data}

Dari literatur tersebut dilakukan analisis sistem konten pembelajaran terhadap isi literatur dan diklasifikasikan menjadi empat, yakni evaluasi penggunaan, konten, pembelajaran daring dan media pembelajaran.

Hasil dari kajian ini diharapkan dapat menjadi rujukan untuk membangun ensiklopedia digital khusus anak dengan kurikulum 2013 sesuai standar pendidikan di Indonesia, selanjutnya akan dijabarkan metode yang digunakan untuk pencarian literatur dan analisis literatur berdasarkan topik yang dijadikan acuan.

\section{A. Metode Pencarian}

Proses pencarian dilakukan pada Google Scholar dengan memasukkan kata kunci utama Wikipedia, ensiklopedia, kurikulum sekolah dasar, konten pendidikan dan media pembelajaran daring. Pencarian juga dilakukan pada situs resmi milik Kementerian Pendidikan dan Kebudayaan untuk menemukan kurikulum dan penilaian pendidikan tingkat dasar. Dari hasil pencarian dilakukan pemilihan literatur berdasarkan yang keseluruhannya mencakup:

a. Literatur yang dipilih dipublikasikan dalam rentang tahun 2016 hingga 2020, yang mengindikasikan kebaruan referensi.

b. Literatur membahas tentang poin penting yang dibutuhkan dalam pengembangan ensiklopedia dengan konten pendidikan.

c. Literatur membahas tentang penggunaan dan potensi media daring untuk pembelajaran.

d. Literatur berisi standar isi kurikulum dan standar penilaian pendidikan untuk sekolah tingkat dasar.

e. Literatur dituliskan dalam Bahasa Inggris dan Bahasa Indonesia.

\section{B. Metode Analisis}

Analisis untuk literatur yang terpilih dilakukan dengan cara menjabarkan inti dari literatur tersebut dalam satu tabel untuk mengklasifikasikannya dalam empat topik. Keempat klasifikasi tersebut meliputi evaluasi penggunaan, konten, pembelajaran daring dan media. Dalam konteks evaluasi penggunaan, dipaparkan analisis mengenai penelitian yang terfokus dengan penggunaan, manfaat, potensi dan perspektif terhadap Wikipedia/ensiklopedia atau media lain. Dalam konteks konten, dipaparkan analisis terhadap topik khusus dari ensiklopedia maupun media lainnya yang masih terkait dengan pendidikan. Dalam konteks pembelajaran daring, dipaparkan analisis mengenai media daring apapun yang dimanfaatkan untuk kebutuhan pendidikan dan dampak dari penggunaan media daring sebagai sarana pendukung pendidikan. Sedangkan dalam konteks media pembelajaran, dipaparkan bentuk media yang digunakan dalam penelitian yang dikaji. Analisis yang dilakukan bertujuan untuk mempermudah mendapatkan informasi pendukung dari literatur-literatur terpilih untuk membangun ensiklopedia digital yang berisi pembelajaran untuk anak sekolah dasar sesuai kurikulum. Hasil dari analisis meliputi informasi yang esensial untuk mengembangkan ensiklopedia sebagai alat pembelajaran. 


\section{HASIL DAN PEMBAHASAN}

Berdasarkan pencarian melalui Google Scholar dan situs resmi Kementerian Pendidikan dan Kebudayaan ditemukan 49 referensi, namun hanya 26 yang lebih sesuai dengan kebutuhan informasi untuk membangun ensiklopedia dengan konten pendidikan. Dari 49 referensi tersebut, terdapat 14 yang tidak memenuhi kriteria rentang tahun dan 9 referensi yang kurang sesuai dan tidak lengkap pembahasannya mengenai ensiklopedia sebagai media pembelajaran. Pada Tabel 1 dipaparkan perbandingan informasi yang diperoleh dari setiap referensi yang dikaji. Tabel 1 memberikan hasil analisis informasi terkait kesimpulan mengenai hal yang penting untuk membangun media pembelajaran.

Dari referensi tersebut, 9 dari 26 referensi mengandung informasi yang dibutuhkan mengenai Wikipedia/ensiklopedia yang meliputi penggunaan ensiklopedia sampai dengan persepsi dosen dan mahasiswa terhadap wikipedia. 13 dari 26 referensi memaparkan informasi tentang kurikulum dan konten yang diangkat sebagai pembahasan dari referensi tersebut, dan 12 dari 26 referensi memaparkan informasi media pembelajaran daring yang meliputi penggunaan, efektifitas dan model media yang digunakan pada referensi tersebut. Pada poin 3.1 akan dilakukan analisis klasifikasi referensi dan digunakan sebagai penyaring informasi untuk membangun sistem konten pembelajaran : ensiklopedia daring sehingga menjadi bermanfaat, disukai dan dapat terus digunakan meskipun sekolah seperti biasa sudah dilaksanakan kembali seperti semula dan pada poin 3.2 akan dilakukan analisis terhadap gap dari referensi yang digunakan secara lebih detail.

\section{A. Analisis Klasifikasi}

Dari hasil kajian literatur, diperoleh empat klasifikasi utama yang digunakan sebagai penyaring informasi untuk membangun ensiklopedia daring dengan konten pendidikan yang efektif untuk anak sekolah dasar. Berikut ini hasil kajian literatur :

Tabel 1. Klasifikasi Literatur

\begin{tabular}{|c|c|c|c|c|c|}
\hline Makalah & Tahun & $\begin{array}{l}\text { Evaluai Penggunaan } \\
\end{array}$ & Konten & Pembelajaran Daring & Media \\
\hline$[1]$ & 2017 & Alasan orang membaca Wikipedia. & & & Wikipedia. \\
\hline$[2]$ & 2018 & $\begin{array}{c}\text { Media pembelajaran tentang } \\
\text { ekologi dan lingkungan. }\end{array}$ & $\begin{array}{c}\text { Ekologi manusia } \\
\text { dan lingkungannya. }\end{array}$ & & Buku. \\
\hline$[3]$ & 2018 & $\begin{array}{l}\text { Ensiklopedia digital sebagai sumber } \\
\text { belajar. }\end{array}$ & $\begin{array}{c}\text { Tumbuhan tingkat } \\
\text { tinggi. }\end{array}$ & & Ensiklopedia Digital \\
\hline [4] & 2018 & & $\begin{array}{l}\text { Pendidikan Agama } \\
\text { Islam dan Budi } \\
\text { Pekerti. }\end{array}$ & $\begin{array}{c}\text { Media literasi dalam } \\
\text { pembelajaran. }\end{array}$ & $\begin{array}{l}\text { Beragam media } \\
\text { pembelajaran. }\end{array}$ \\
\hline$[5]$ & 2019 & & Pelajaran biologi. & $\begin{array}{c}\text { Konten e-learning } \\
\text { berbasis SCORM } \\
\text { (Shareable Content } \\
\text { Object Reference Model). }\end{array}$ & $\begin{array}{l}\text { Microsoft Word dan } \\
\text { Microsoft Power } \\
\text { Point. }\end{array}$ \\
\hline$[6]$ & 2018 & & $\begin{array}{c}\text { Pendidikan Jasmani } \\
\text { dan Olahraga. }\end{array}$ & & $\begin{array}{l}\text { Aplikasi Mobile } \\
\text { Learning. }\end{array}$ \\
\hline [7] & 2017 & $\begin{array}{c}\text { Wikipedia sebagai situs warisan } \\
\text { budaya. }\end{array}$ & Warisan budaya. & Crowd Sourcing & Wikipedia. \\
\hline [8] & 2017 & $\begin{array}{c}\text { Wikipedia sebagai sumber } \\
\text { pengetahuan dari Open-domain } \\
\text { Question Answering System. }\end{array}$ & & & \\
\hline [9] & 2018 & $\begin{array}{l}\text { Wikipedia sebagai sumber } \\
\text { pengetahuan tentang penyakit. }\end{array}$ & $\begin{array}{l}\text { Penyakit dan } \\
\text { gejalanya. }\end{array}$ & & \\
\hline$[10]$ & 2016 & $\begin{array}{l}\text { Wikipedia sebagai media } \\
\text { kolaborasi daring untuk } \\
\text { pengetahuan bersama. }\end{array}$ & & Crowd Sourcing & \\
\hline$[11]$ & 2020 & $\begin{array}{l}\text { Analisis tingkat kesiapan pengguna } \\
\text { ensiklopedia anak. }\end{array}$ & & Guru sebagai kontributor. & Ensiklopedia Digital. \\
\hline$[12]$ & 2018 & $\begin{array}{c}\text { Persepsi dosen dan mahasiswa } \\
\text { terhadap penggunaan Wikipedia } \\
\text { sebagai sumber informasi digital } \\
\text { ilmiah. }\end{array}$ & & & \\
\hline [13] & 2020 & & . & $\begin{array}{c}\text { Konten media sosial } \\
\text { sebagai alternatif } \\
\text { pembelajaran } \\
\end{array}$ & Media sosial. \\
\hline [14] & 2017 & & Tematik. & & Buku. \\
\hline$[15]$ & 2016 & & $\begin{array}{c}\text { Standar isi } \\
\text { pendidikan dasar } \\
\text { dan menengah. }\end{array}$ & & \\
\hline [16] & 2016 & & $\begin{array}{l}\text { Standar penilaian } \\
\text { pendidikan. }\end{array}$ & & \\
\hline$[17]$ & 2017 & & $\begin{array}{l}\text { Gerakan literasi } \\
\text { nasional. }\end{array}$ & & \\
\hline [18] & 2016 & & $\begin{array}{l}\text { Gerakan literasi } \\
\text { sekolah dasar. }\end{array}$ & & \\
\hline [19] & 2020 & & Modul literasi dan & Program pembelajaran & E-book. \\
\hline
\end{tabular}


ISSN 2085-4552

\begin{tabular}{|c|c|c|c|c|c|}
\hline & & & numerasi. & jarak jauh. & \\
\hline [20] & 2020 & $\begin{array}{l}\text { Pemanfaatan teknologi informasi } \\
\text { untuk pembelajaran daring. }\end{array}$ & & $\begin{array}{l}\text { Tantangan dan peluang } \\
\text { pembelajaran daring pada } \\
\text { masa pandemi Covid-19. }\end{array}$ & $\begin{array}{c}\text { Edmodo, EdLink, } \\
\text { Moodle, Google } \\
\text { Classroom dan } \\
\text { Schoology. }\end{array}$ \\
\hline [21] & 2020 & $\begin{array}{c}\text { Pemanfaatan kemajuan IT guna } \\
\text { mendukung proses belajar } \\
\text { mengajar. }\end{array}$ & & $\begin{array}{c}\text { Dampak positif } \\
\text { pembelajaran daring di } \\
\text { Indonesia. } \\
\end{array}$ & \\
\hline [22] & 2020 & $\begin{array}{l}\text { Penggunaan aplikasi Ruang Guru } \\
\text { terhadap minat belajar siswa SMA. }\end{array}$ & & $\begin{array}{l}\text { Minat belajar daring } \\
\text { menggunakan aplikasi } \\
\text { Ruang Guru. }\end{array}$ & Ruang Guru. \\
\hline [23] & 2020 & & & $\begin{array}{l}\text { Model dan desain } \\
\text { pembelajaran daring. }\end{array}$ & $\begin{array}{c}\text { Zoom, Google } \\
\text { Classroom, Webex } \\
\text { Meeting. } \\
\end{array}$ \\
\hline [24] & 2020 & & & $\begin{array}{c}\text { Variasi pembelajaran } \\
\text { daring. }\end{array}$ & $\begin{array}{c}\text { Zoom, Google } \\
\text { Classroom. }\end{array}$ \\
\hline [25] & 2018 & & & $\begin{array}{c}\text { Pengaruh komunikasi } \\
\text { media daring aplikasi } \\
\text { Ruangguru terhadap } \\
\text { peningkatan prestasi } \\
\text { belajar. }\end{array}$ & Ruang Guru. \\
\hline [26] & 2020 & & & $\begin{array}{c}\text { Kehadiran sosial } \\
\text { Ruangguru dan } \\
\text { kemampuan beradaptasi } \\
\text { dengan kondisi yang } \\
\text { terjadi. }\end{array}$ & Ruang Guru. \\
\hline [27] & 2017 & $\begin{array}{l}\text { Pengembangan media pembelajaran } \\
\text { komik digital. }\end{array}$ & $\begin{array}{l}\text { Ilmu Pengetahuan } \\
\text { Sosial. } \\
\end{array}$ & & Komik Digital. \\
\hline [28] & 2018 & $\begin{array}{l}\text { Game android untuk meningkatkan } \\
\text { minat belajar matematika. }\end{array}$ & Matematika. & & Game. \\
\hline [29] & 2020 & $\begin{array}{c}\text { Pengaruh media pembelajaran } \\
\text { daring dalam pemahaman dan } \\
\text { minat belajar siswa. }\end{array}$ & Fisika. & $\begin{array}{l}\text { Penerapan media } \\
\text { pembelajaran daring. }\end{array}$ & \\
\hline [30] & 2017 & $\begin{array}{l}\text { Pengembangan aplikasi media } \\
\text { pembelajaran game interaktif. }\end{array}$ & Bahasa Inggris. & & Game. \\
\hline
\end{tabular}

Dari hasil analisis dalam sisi pemanfaatan atau penggunaan terdapat 16 penelitian yang memanfaatkan maupun mengembangkan berbagai media untuk penelitiannya. Terdapat 1 penelitian [1] yang memanfaatkan media Wikipedia untuk mengungkap mengapa orang mau membaca Wikipedia. Terdapat 9 penelitian yang memanfaatkan berbagai media untuk dikembangkan lebih lanjut seperti pada penelitian [2] yang mengembangkan media pembelajaran tentang ekologi manusia dan lingkungannya dalam bentuk buku, penelitian [3], [7]-[10] mengembangkan ensiklopedia dengan beragam konten di dalamnya. Terdapat 1 penelitian yang mengembangkan komik digital sebagai media pembelajaran ilmu pengetahuan sosial [27], dan 2 penelitian yang mengembangkan game sebagai media pembelajaran seperti pada penelitian [28] dan [30]. Terdapat 1 penelitian yang menganalisis tingkat kesiapan anak terhadap ensiklopedia digital [11] dan 5 penelitian yang membahas pemanfaatan dan penggunaan beragam media yang digunakan seperti pada penelitian [12] yang membahas persepsi dosen dan mahasiswa terhadap penggunaan Wikipedia, penelitian [20], [21] membahas pemanfaatan teknologi informasi dan penelitian [22], [29] yang menganalisis media terhadap minat belajar siswa.

Berdasarkan analisis terhadap pembelajaran daring ditemukan berbagai media yang digunakan pada pembelajaran daring seperti pada penelitian [4], berdasarkan hasil survei yang dilakukan pada penelitian [20] menyatakan 50\% mahasiswa belum memiliki laptop dan $80 \%$ mahasiswa menyatakan susah mendapatkan sinyal dan boros penggunaan paket data. Pada penelitian [24] ditemukan kelebihan dan kekurangan dari pembelajaran daring yang meliputi :

Kelebihan pembelajaran daring :

- Menyenangkan dan menarik.

- Efektif dan lebih mudah dimengerti.

- Belajar sambil bermain.

- Belajar hal baru secara daring.

- Tidak lelah dan bisa santai dalam belajar.

- Lebih semangat dalam belajar

Kekurangan pembelajaran daring :

- Siswa bosan belajar di rumah dan senang belajar di sekolah.

- Kesulitan dalam koneksi internet.

- Siswa tidak bisa berdiskusi dan bertemu secara langsung.

- Siswa lebih mengerti penjelasan dari guru secara langsung.

- Siswa merasa banyak beban tugas yang diberikan guru.

- Siswa merasa pusing dan lelah terlalu sering berhadapan dengan gadget. 


\section{B. Analisis Media}

Hasil analisis diperoleh 6 media berbeda yang digunakan pada penelitian sebelumnya. Gambar 1 menunjukkan banyaknya media yang masih banyak digunakan pada penelitian sebelumnya.

Terdapat 3 penelitian yang memanfaatkan penggunaan media ensiklopedia seperti pada penelitian [3] yang mengembangkan ensiklopedia digital mengenai tumbuhan tingkat tinggi, penelitian [7] yang mengembangkan ensiklopedia mengenai warisan budaya dan penelitian [11] yang menganalisis tingkat kesiapan anak terhadap ensiklopedia digital.

Media dalam bentuk buku juga masih digunakan seperti pada penelitian [2] yang mengembangkan media pembelajaran tentang ekologi manusia dan lingkungannya. Ada satu penelitian yang mengembangkan media pembelajaran ilmu pengetahuan sosial dengan media komik digital yakni pada penelitian [27].

Sosial media juga menjadi salah satu media yang menjadi pilihan sebagai media pembelajaran, seperti pada penelitian [13] yang meneliti konten media sosial Twitter. Ada 2 penelitian yang memanfaatkan game sebagai media pembelajaran seperti pada penelitian [28] yang mengembangkan game pada Android untuk pembelajaran matematika dan pada penelitian [30] yang mengembangkan media pembelajaran game interaktif Bahasa Inggris.

Aplikasi menjadi media yang paling banyak dimanfaatkan maupun dikembangkan dari semua penelitian di atas. Terdapat 8 penelitian memanfaatkan atau mengembangkan aplikasi sebagai media dan fasilitas pendukung pembelajaran. Pada penelitian [5] memanfaatkan Microsoft Word dan Microsoft Power Point untuk pembelajaran daring berbasis SCORM (Shareable Content Object Reference Model). Pada penelitian [6] dikembangkan aplikasi mobile learning untuk membantu meningkatkan pembelajaran pendidikan jasmani dan olahraga. Terdapat 3 penelitian yang memanfaatkan aplikasi Google Classroom sebagai media pembelajaran seperti pada penelitian [20], [23] dan [24]. Terdapat 3 penelitian yang menggunakan Ruang Guru sebagai objek penelitiannya yang meneliti minat belajar daring [22], peningkatan prestasi belajar [25] dan kemampuan beradaptasi dari aplikasi Ruang Guru [26].
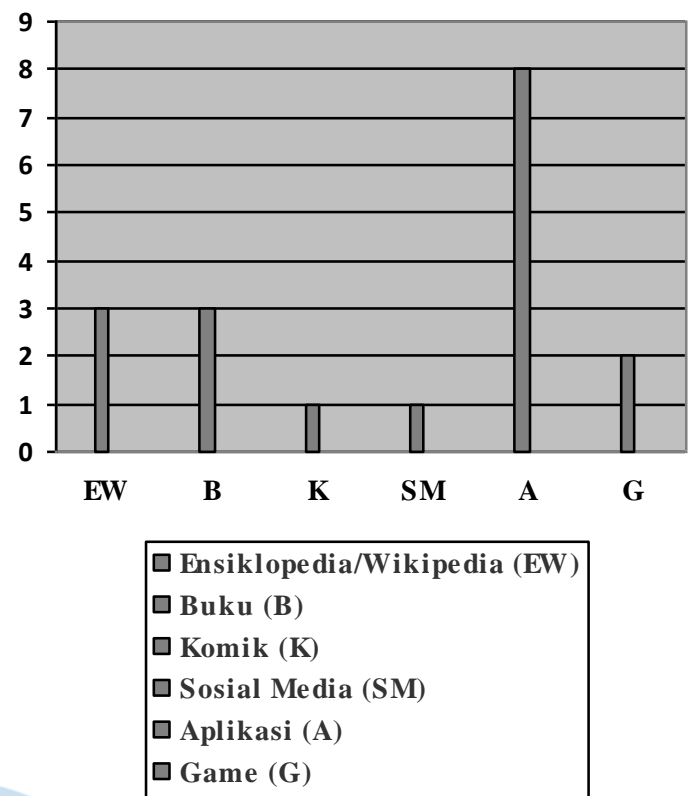

Gambar 2. Hasil analisis media

\section{Analisis Gap Literatur}

Pada analisis gap ini penulis akan membahas terkait perbandingan klasifikasi yang gunakan sebagai pertanyaan pernelitian yang meliputi evakuasi pengguna, konten, pembelajaran daring, dan media berdasar referensi yang dihimpun terdapat potensi dari pemanfaatan ensiklopedia daring untuk mendukung pembelajaran, Hal ini ditunjukan dari 30 penelitian sebelumnya didapatkan 9 referensi yang membahas mengenai Wikipedia dan ensiklopedia dalam konteks penggunaan maupun pengembangan. Berdasarkan paparan Tabel 1 di atas, didapatkan alasan orang mengakses Wikipedia karena akses yang mudah dan ketersediaan informasi yang lengkap. Banyak penelitian sebelumnya yang berfokus pada kolaborasi dalam pemanfaatan Wikipedia untuk dikembangkan dengan konten tertentu. Ada satu penelitian yang mengembangkan ensiklopedia untuk anak, namun masih dalam bentuk buku dan belum dalam bentuk media digital.

Dalam konteks konten didapatkan 14 referensi yang mencakup pembahasan mengenai bidang spesifik dan 2 referensi mengenai peraturan pemerintah yang mengatur tentang standar isi kurikulum dan standar penilaian untuk pendidikan sekolah tingkat dasar. Belum ada penelitian yang membahas media pembelajaran dengan konten yang sesuai dengan kurikulum yang berlaku di Indonesia.

Sedangkan dalam konteks pembelajaran daring, didapatkan 12 referensi yang mengangkat topik mengenai media daring. Media daring tidak hanya digunakan sebagai media pembelajaran, dapat juga dimanfaatkan untuk hal lain. Penelitian yang membahas tentang media daring banyak memaparkan kelebihan dan kekurangan dari pembelajaran daring 
itu sendiri, selain itu ada juga yang membahas tentang tingkat kesiapan pengguna dan dampak yang ditimbulkan dari penggunaan media daring.

Berdasarkan hasil analisis, belum ada penelitian yang membahas semua klasifikasi pada Tabel 1 sekaligus, belum banyak penelitian tentang ensiklopedia digital untuk pendikan dan dapat disimpulkan bahwa pembelajaran daring memiliki potensi tinggi untuk meningkatkan minat belajar anak asalkan konten yang ditujukan untuk anak-anak tepat sasaran. Dengan mempertimbangkan hal hal penting yang mendukung pada pembuatan konten pembelajaran dapat menciptakan sistem konten sistem pembelajaran yang sesuai untuk mendukung pembelajaran, pembelajaran daring menggunakan media ensiklopedia daring diharapkan dapat meningkatkan minat belajar bagi anak dan pembelajaran daring menjadi kebiasaan baru untuk jangka waktu yang panjang.

\section{SIMPULAN}

Ensiklopedia sebagai media pembelajaran daring memiliki potensi yang baik untuk menjadi alat bantu bagi siswa sekolah, terutama pada tingkat dasar.Hal ini didapatkan dari analisis yang dapat kita lihat hubungan keterkaitan dari klasifikasinya sebagai berikut :

- Melihat Potensi dari evaluasi pengguna

- Karakteristik bidang ilmu dari konten

- Peran media belajar dari Pembelajaran daring

- Potensi Media dari analisis media

Ensiklopedia digital dapat menjadi pengganti buku sekolah bagi anak mengingat perkembangan teknologi saat ini yang sangat pesat. Untuk membangun ensiklopedia digital yang baik untuk siswa pendidikan tingkat dasar dan dapat bertahan lama dibutuhkan kolaborasi antara guru-guru di sekolah untuk membuat konten mengenai mata pelajaran yang diampu pada ensiklopedia tersebut. Konten mata pelajaran harus dibuat semenarik mungkin agar dapat meningkatkan minat belajar dan prestasi akademik anak. Konten juga harus dibuat kreatif dan tidak membosankan agar anak terus tertarik untuk belajar hal-hal baru.

Melalui ensiklopedia digital, siswa diharapkan dapat menerima model baru pembelajaran daring dengan konten yang disediakan melalui teks, gambar dan video. Peran orang tua juga menjadi hal yang harus diperhatikan dalam membimbing anak menggunakan perangkat untuk mengakses ensiklopedia digital tersebut agar anak tidak salah menggunakan perangkat untuk mengakses hal-hal yang negatif. Ensiklopedia digital dengan konten pendidikan belum banyak dikembangkan, terutama di Indonesia, sudah ada beberapa penelitian yang memanfaatkan media untuk pembelajaran namun belum sesuai dengan kurikulum sekolah. Ensiklopedia digital tidak akan bisa dimanfaatkan dengan maksimal tanpa peran guru dan orang tua.

\section{DAFTAR PUSTAKA}

[1] P. Singer et al., "Why we read Wikipedia," 26th Int. World Wide Web Conf. WWW 2017, pp. 1591-1600, 2017, doi: 10.1145/3038912.3052716.

[2] G. D. Prameswari Sutanto, B. R. Noviadji, and C. B. Susilo, "Perancangan Buku Ensiklopedia Ekologi \& Lingkungan Tentang Manusia dan Lingkungannya Untuk Anak Usia 9-12 Tahun," Artika, vol. 2, no. 1, pp. 1-11, 2018, doi: 10.34148/artika.v2i1.71.

[3] K. Azis, M. Wiharto, and S. Saenab, "Ensiklopedia Digital Tumbuhan Tingkat Tinggi Dengan Fitur QR Code Sebagai Sumber Belajar Dunia Tumbuhan," Biol. Teach. Learn., vol. 1, no. 2, pp. 109-120, 2018.

[4] U. Wahidin, "Implementasi Literasi Media dalam Proses Pembelajaran Pendidikan Agama Islam dan Budi Pekerti," Implementasi Literasi Media Dalam Proses Pembelajaran Pendidik. Agama Islam Dan Budi Pekerti, pp. 229-244, 2018.

[5] S. H. Bariah and S. M. Sidik, "Penerapan Konten Elearning Berbasis SCORM Untuk Meningkatkan Efektivitas Pembelajaran," vol. 5, pp. 1-10, 2019.

[6] Y. Satria, S. Saptadi, H. Prastawa, and P. Jasmani, "Pengembangan Aplikasi Mobile Learning Sebagai Pelengkap Pembelajaran SMA Negeri 2 Semarang (Studi Kasus: Mata Pelajaran Pendidikan Jasmani dan Olahraga)," pp. 1-12, 2018

[7] C. Pentzold, E. Weltevrede, M. Mauri, D. Laniado, A. Kaltenbrunner, and E. Borra, "Digging Wikipedia: The online encyclopedia as a digital cultural heritage gateway and site," J. Comput. Cult. Herit., vol. 10, no. 1, pp. 119, 2017, doi: 10.1145/3012285.

[8] D. Chen, A. Fisch, J. Weston, and A. Bordes, "Reading Wikipedia to answer open-domain questions," ACL 2017 - 55th Annu. Meet. Assoc. Comput. Linguist. Proc. Conf. (Long Pap., vol. 1, pp. 1870-1879, 2017, doi: 10.18653/v1/P17-1171.

[9] E. P. G. Del Valle, G. L. Garcia, L. Prieto Santamaria, M. Zanin, E. M. Ruiz, and A. R. González, "Evaluating Wikipedia as a Source of Information for Disease Understanding," Proc. - IEEE Symp. Comput. Med. Syst., vol. 2018-June, pp. 399-404, 2018, doi: 10.1109/CBMS.2018.00076.

[10] J. Yun, S. H. Lee, and H. Jeong, "Intellectual interchanges in the history of the massive online openediting encyclopedia, Wikipedia," Phys. Rev. E, vol. 93, no. 1, 2016, doi: 10.1103/PhysRevE.93.012307.

[11] R. D. Kristy, E. D. Wahyuni, and N. Hayatin, "Analisis Tingkat Kesiapan Pengguna Ensiklopedia Anak Dengan Menggunakan Metode Technology Readiness Index," Repositor, vol. 2, no. 2, pp. 129-136, 2020.

[12] E. Syafrita, "Persepsi Dosen dan Mahasiswa Program Studi Informasi Perpustakaan Dan Kearsipan Terhadap Wikipedia Sebagai Sumber Informasi Digital," no. September, pp. 99-103, 2018.

[13] A. R. Randisa and A. Nurmandi, "Analisis Konten Media Sosial Twitter Sarana Pendidikan di Indonesia Study Kasus Ruang Guru," J. Ilm. Tata Sejuta STIA Mataram, vol. 6, no. 2, pp. 291-601, 2020, doi: 10.32666/tatasejuta.v6i2.135.

[14] Suyono, T. Harsiati, and I. S. Wulandari, "Implementasi Gerakan Literasi Sekolah Pada Pembelajaran Tematik di Sekolah Dasar," Sekol. Dasar Kaji. Teor. dan Prakt. Pendidik., pp. 116-123, 2017.

[15] Menteri Pendidikan dan Kebudayaan, Peraturan Menteri Pendidikan dan Kebudayaan Republik Indonesia Nomor 21 Tahun 2016 Tentang Standar Isi Pendidikan Dasar 
dan Menengah. Indonesia, 2016.

[16] Menteri Pendidikan dan Kebudayaan, Peraturan Menteri Pendidkan dam Kebudayaan Republik Indonesia Nomor 23 Tahun 2016 Tentang Standar Penilaian Pendidikan. Indonesia, 2016.

[17] Kementerian Pendidikan dan Kebudayaan, Panduan Gerakan Literasi Nasional. Jakarta: Kementerian Pendidikan dan Kebudayaan, 2017.

[18] Kementerian Pendidikan dan Kebudayaan and Direktorat Jenderal Pendidikan Dasar dan Menengah, Panduan Gerakan Literasi Sekolah di Sekolah Dasar. Jakarta: Direktorat Jenderal Pendidikan Dasar dan Menengah, Kementerian Pendidikan dan Kebudayaan, 2016.

[19] Pusmenjar, Modul Belajar Siswa Kelas 1 Tema 1 Diriku Sub Tema 1 Keluarga, Modul Belajar Literasi dan Numerasi Jenjang SD Program Pembelajaran Jarak Jauh, Modul. Jakarta: Kementerian Pendidikan dan Kebudayaan, 2020.

[20] N. K. Suni Astini, "Tantangan Dan Peluang Pemanfaatan Teknologi Informasi Dalam Pembelajaran Online Masa Covid-19," Cetta J. Ilmu Pendidik., vol. 3, no. 2, pp. 241-255, 2020, doi: 10.37329/cetta.v3i2.452.

[21] Y. Pujilestari, "Dampak Positif Pembelajaran Online Dalam Sistem Pendidikan Indonesia Pasca Pandemi Covid-19," Adalah, vol. 4, no. 1, pp. 49-56, 2020, [Online].

Available: http://journal.uinjkt.ac.id/index.php/adalah/article/view/1 5394/7199.

[22] Y. Violita, "Penggunaan Aplikasi Ruang Guru terhadap Minat Belajar Siswa SMA ( Studi Korelasional Pengaruh Penggunaan Aplikasi Ruangguru terhadap Minat Belajar Siswa SMA Negeri 1 Berastagi ),” 2020.

[23] P. Marbun, "Disain Pembelajaran Online Pada Era Dan Pasca Covid-19," CSRID J., vol. 12, no. 2, pp. 129-142, 2020, [Online]. Available: http://csrid.potensiutama.ac.id/index.php/CSRID/article/view/408.

[24] E. Pujiasih, "Membangun Generasi emas dengan Variasi Pembelajaran Online di Masa Pandemi Covid-19,' Ideguru J. Karya Ilm. Guru, vol. 5, no. 1, pp. 42-48, 2020.
[25] E. Langi, L. N. S., and L. Tulung, "Pengaruh Komunikasi Media Online Aplikasi Ruang Guru Pt. Ruang Raya Indonesia Terhadap Peningkatan Prestasi Belajar Siswa Sma Negeri 1 Manado," Acta Diurna Komun., vol. 1, no. 3, pp. 1-16, 2018, [Online]. Available: https://ejournal.unsrat.ac.id/index.php/actadiurnakomunik asi/article/view/25077/24778

[26] R. A. Fattah and F. K. Sujono, "Social Presence of Ruangguru in Social Media during Covid-19 Pandemic," J. Messenger, vol. 12, no. 2, p. 180, 2020, doi: 10.26623/themessenger.v12i2.2276.

[27] E. Sukmanasa, T. Windiyani, and L. Novita, "Pengembangan Media Pembelajaran Komik Digital Pada Mata Pelajaran Ilmu Pengetahuan Sosial Bagi Siswa Kelas V Sekolah Dasar Di Kota Bogor," J. Pendidik. Sekol. Dasar, vol. 3, no. 2, p. 171, 2017, doi: 10.30870/jpsd.v3i2.2138.

[28] M. S. Itqan, "Pendekatan Game Android Untuk Meningkatkan Minat Belajar Matematika Siswa Sekolah Dasar," J. EduMatSains, vol. 2, no. 2, pp. 161-170, 2018, [Online]. Available: http://ejournal.uki.ac.id/index.php/edumatsains/article/vie w/604.

[29] S. Maulidina and Y. B. Bhakti, "Pengaruh Media Pembelajaran Online Dalam Pemahaman Dan Minat Belajar Siswa Pada Konsep Pelajaran Fisika," ORBITA J. Kajian, Inov. dan Apl. Pendidik. Fis., vol. 6, no. 2, p. 248, 2020, doi: 10.31764/orbita.v6i2.2592.

[30] A. R. Nursifa, A. Orinda, and S. S. Pritanti, "Media Pembelajaran Interaktif Bahasa Inggris Kelas V Sekolah Dasar Negeri 02 Cinere," J. CoreIT J. Has. Penelit. Ilmu Komput. dan Teknol. Inf., vol. 3, no. 1, p. 9, 2017, doi: 10.24014/coreit.v3i1.3381.

[31] H. Hendrik, dan A. Hamzah. Flipped Classroom in Programming Course: A Systematic Literature Review. International Journal Of Emerging Technologie In Learning (IJET), 16(02), pp. 220-236. 2021. doi:http://dx.doi.org/10.3991/ijet.v16i02.15229 